\title{
Influence of the Activator Concentration and Solid/Liquid Ratio on the Strength and Shrinkage Characteristics of Alkali-Activated Slag Geopolymer Pastes
}

\author{
Zikai Xu, ${ }^{1}$ Jinchao Yue, ${ }^{1}$ Guanhong Pang $\mathbb{D}^{1},{ }^{1}$ Ruixia Li, ${ }^{1}$ Peng Zhang, ${ }^{1}$ and Shengtang Xu $\mathbb{D}^{2}$ \\ ${ }^{1}$ School of Water Conservancy Engineering, Zhengzhou University, Zhengzhou 450001, China \\ ${ }^{2}$ Xinyang Highway Development Center, Xinyang 464000, China \\ Correspondence should be addressed to Shengtang Xu; xust0326@zzu.edu.cn
}

Received 5 January 2021; Revised 25 January 2021; Accepted 1 February 2021; Published 10 February 2021

Academic Editor: Jiaolong Ren

Copyright ( $\odot 2021$ Zikai Xu et al. This is an open access article distributed under the Creative Commons Attribution License, which permits unrestricted use, distribution, and reproduction in any medium, provided the original work is properly cited.

\begin{abstract}
Geopolymers have distinct advantages such as having energy-saving properties, being an environmentally protective material, and having high mechanical strength and durability. However, the shrinkage of the geopolymer materials is one of the major problems to affect its practical application. In this study, blast furnace slag-based geopolymer pastes were prepared using sodium silicate and sodium hydroxide as activators to investigate the effect of the activator concentration and solid/liquid ratio on strength and shrinkage properties. For a better understanding of the reaction mechanism and microstructure of the geopolymer pastes, a multitechnique approach including scanning electron microscopy, X-ray diffraction, and Fourier transform infrared spectra was carried out. The results showed that the geopolymers compressive strength increased significantly as the activator concentration increased. The increase in activator concentration first increased the flexural strength and then decreased and reached the maximum when the activator concentration was $40 \%$. A higher activator concentration, as well as a lower solid/liquid ratio, generally led to serious geopolymers drying shrinkage. These findings are expected to be ascribed from the changes in the content of the alkali-activated product (i.e., hydrate calcium aluminosilicate), which depends on the activator concentration. The increase in C-A-S-H gel (hydrate calcium aluminosilicate) compacts paste densifiers but causes shrinkage fracture concerns. These results provide an appropriate proportion for alkali-activated slag geopolymer pastes with better mechanical strength and antidryshrinkage cracking properties, which are beneficial for the further applications of geopolymer materials.
\end{abstract}

\section{Introduction}

Geopolymers are formed by the reaction of alkali hydroxide or silicate solution with solid aluminosilicate to form a three-dimensional network structure consisting of silica tetrahedrons and aluminum oxide tetrahedrons [1-3]. Geopolymers exhibits excellent characteristics including high strength, low $\mathrm{CO}_{2}$ emissions, excellent corrosion resistance, and durability, compared to traditional cementitious binders [3-5]. The geopolymerization process is more environmentally friendly and may be carried out under ambient conditions or at low temperatures. The raw materials used for geopolymerization do not require extra energy consumption and are industrial byproducts such as fly ash and blast furnace slags [6].
Therefore, geopolymers have the potential to partially replace cement when preparing concrete.

Geopolymer strength has been examined in many previous studies. Atiş et al. [7] found that the mechanical strength of alkali-activated slag materials decreased according to the activators used: $\mathrm{Na}_{2} \mathrm{O} \bullet \mathrm{nSiO}_{2}>\mathrm{NaOH}>\mathrm{Na}_{2} \mathrm{CO}_{3}$. Aydın Baradan [8] also found that alkali-activated slag pastes using $\mathrm{Na}_{2} \mathrm{O} \bullet \mathrm{nSiO}_{2}$ as an activator had higher compressive strength, higher fluidity, lower adsorption water, lower porosity, and a larger setting time range than those using $\mathrm{NaOH}$. Liu et al. [9] reported that when the water/cement ratio increased from 0.30 to 0.38 , the compressive strength of the geopolymer decreased from $82.9 \mathrm{MPa}$ to $63.4 \mathrm{MPa}$, and the initial and final setting times increased from 10 to $13 \mathrm{~min}$ to 22 and 
26 min, respectively. Cheng et al. [10] thought that the solid reactants increased and the porosity decreased with increasing solid/liquid ratio, which led to an increase in strength. While Heah et al. [11] drew the opposite conclusion using an orthogonal test, and the different results may have been caused by the different solid/liquid ratio adjustment ranges. Moreover, the results showed that the activator concentration, sodium silicate modulus, alkali metal ions, and solid/liquid ratio influenced the geopolymers mineral composition, microstructure, and mechanical properties [12-17]. The activator concentration is the key factor that determines the properties of geopolymers. Tuyan et al. [18] suggested that geopolymers compressive strength increased with increasing activator concentration and decreased with increasing sodium silicate modulus when $\mathrm{Na}_{2} \mathrm{O}$ concentration was lower than $10 \%$. The optimum activator concentration corresponded to an $M$ (molar ratio of silica to sodium oxide) ratio of 1.6 and $\mathrm{Na}_{2} \mathrm{O}$ content of $10 \%$ by binder weight. However, Alonso and Palomo [13] argued that increasing the activator concentration would delay the polymerization time and limit the ion mobility and the formation of hard structures, decreasing the mechanical properties.

In addition, geopolymers shrinkage during the setting and hardening processes is relatively obvious, which limits the geopolymers application [19, 20]. Excessive shrinkage may lead to cracking, thereby reducing not only the strength and stiffness but also the service life of the structure [21-23]. Many studies regarding the shrinkage behavior of geopolymers have been conducted in the last decade. Deb et al. [24] found that the drying shrinkage of geopolymers strain increased as the content of fly ash increased. Ridtirud et al. [25] found that the curing temperature and solid/liquid ratio played key roles in determining the drying shrinkage of fly ash-based geopolymers. Mermerdaş et al. [26] suggested that geopolymers with a higher content of binders and $\mathrm{NaOH}$ molarities showed a lower drying shrinkage, resulting in an increase in autogenous shrinkage. Ling et al. [27] thought the drying shrinkage of fly ash-based geopolymer pastes increased with decreasing module and activator concentration, but the total porosity is slightly lower. Kamhangrittirong et al. [28] reported that the drying shrinkage significantly decreased with increasing fly ash content and decreasing sodium hydroxide concentration. When the ratio of sodium silicate to sodium hydroxide was 1.0, the shrinkage resistance of the geopolymer was the best.

In this study, we investigated the effects of the activator concentration and solid/liquid ratio on the mechanical strength development and shrinkage behavior of slag-based geopolymer pastes to provide an experimental basis and references for the performance optimization of geopolymers.

\section{Materials and Methods}

2.1. Materials. Blast furnace slag powder is the main material to prepare the geopolymer pastes. The specific surface area of the slag powder is $436 \mathrm{~m}^{2} / \mathrm{kg}$. The chemical composition is analysed by $\mathrm{X}$-ray fluorescence spectrometer, and the test results are shown in Table 1 which consist of $43.41 \%$ $\mathrm{CaO}, 22.99 \% \mathrm{SiO}_{2}$, and $11.60 \% \mathrm{Al}_{2} \mathrm{O}_{3}$. Alkali activator is prepared by blending sodium silicate solution $\left(\mathrm{Na}_{2} \mathrm{O}=8.5\right.$ wt $\%, \mathrm{SiO}_{2}=26.8 \mathrm{wt} \%$, and sodium silicate modulus $\mathrm{SiO}_{2} /$ $\mathrm{Na}_{2} \mathrm{O}$ (molar mass ratio $)=3.25$ ) with sodium hydroxide pellets (99 wt\% purity).

2.2. Geopolymer Pastes Preparation. The preparation of geopolymer pastes is similar to the process of cement pastes preparation. First, sodium silicate solution and solid sodium hydroxide are prepared into alkali activators with a modulus of 1.5 and 2. The concentration of alkali activators is adjusted to $30,40,50,60$, and $70 \%$ (wt\%) by adding deionized water. This activator is cooled to room temperature $(24 \mathrm{~h})$ and mixes with slags with solid/liquid ratios of $1.5: 1,1.25: 1$ and $1: 1$. After $5 \mathrm{~min}$ of stirring $(2 \mathrm{~min}$ at a low speed and $3 \mathrm{~min}$ at high speed), the mixtures are cast into a mould with a size of $\varnothing 50 \times 50 \mathrm{~mm}$ for compressive strength tests and a mould with a size of $40 \times 40 \times 160 \mathrm{~mm}$ for testing the flexural strength and drying shrinkage. The specimens are cured in a standard curing box $\left(20^{\circ} \mathrm{C}\right.$ and $\left.95 \% \mathrm{RH}\right)$ for $24 \mathrm{~h}$ and demoulded. Then, the specimens are stored under ambient conditions until testing (3, 7, and $28 \mathrm{~d})$.

\subsection{Test Methods}

2.3.1. Mechanical Properties. The compressive strength and flexural strength of the specimens are determined after 3,7 , and $28 \mathrm{~d}$ of curing via microcomputer controlled pressure testing systems, according to the standard of Cement-Test Methods-Determination of strength (ISO 679:2009). The values of the compressive strength and flexural strength are the averages of six separate tests. Data deviating more than $10 \%$ from the mean are eliminated.

2.3.2. Setting Time. The setting time is tested according to a standard method for Portland cement normal consistency, setting time, and soundness water requirements $(\mathrm{GB} / \mathrm{T}$ 1346-2011). The setting time is measured by a Vicat apparatus, and the test interval is $5 \mathrm{~min}$. The values of the setting time are the averages of three separate tests.

2.3.3. Shrinkage Properties. The shrinkage property test is based on the modified ring constraint method [29]. The evenly stirred geopolymer pastes are poured into a mould composed of a resin board with a size of $200 \times 200 \times 3 \mathrm{~mm}$ with an inscribed circle diameter of $150 \mathrm{~mm}$ and a glass bottom plate. After setting for $24 \mathrm{~h}$ at room temperature, the morphology and the number of cracked blocks are observed and counted.

According to the JC/T 603-2004 standard test method for mortar drying shrinkage, the drying shrinkage is reported by measuring three specimens to obtain an average value. The specimens continue to be cured in a constant temperature water bath at $20^{\circ} \mathrm{C}$ for $2 \mathrm{~d}$ after demoulding. Then, the test pieces are removed, the water on their surfaces is wiped, and their initial length is measured with an 
TABLE 1: Chemical composition of the blast furnace slag (wt\%).

\begin{tabular}{lcccccc}
\hline Oxide & $\mathrm{CaO}$ & $\mathrm{SiO}_{2}$ & $\mathrm{Al}_{2} \mathrm{O}_{3}$ & $\mathrm{MgO}$ & $\mathrm{SO}_{3}$ & $\mathrm{Fe}_{2} \mathrm{O}_{3}$ \\
\hline Content (\%) & 43.41 & 22.99 & 11.60 & 6.47 & 2.31 & 1.19 \\
\hline
\end{tabular}

accuracy of $0.001 \mathrm{~mm}$. The samples are then put into drying and shrinking box for curing at a temperature of $20 \pm 2^{\circ} \mathrm{C}$ and relative humidity of $60 \pm 5 \%$. The length of the samples after drying is tested with an accuracy of $0.001 \mathrm{~mm}$. Drying shrinkage is determined from equation (1), where $L_{0}(\mathrm{~mm})$ is the demoulded length, $L_{d}(\mathrm{~mm})$ is the measured length, and $160(\mathrm{~mm})$ is the effective length of the specimens without two head nails. The values of the drying shrinkage are the averages of three separate tests.

$$
\text { drying shrinkage }=\frac{L_{0}-L_{d}}{160} \times 100 .
$$

2.3.4. Microscopic Test. A KYKY-EM6200 scanning electron microscope is used to analyse the microstructure and morphology of the geopolymer pastes. MiniFlex 600 X-ray diffraction (XRD) is used to analyse the diffraction pattern of the geopolymer pastes. Fourier transform infrared spectroscopy (FTIR) is recorded on a Bruker VERTEX 70v in transmittance mode with a frequency between 4000 and $500 \mathrm{~cm}^{-1}$ to analyse the geopolymer functional group composition via the $\mathrm{KBr}$ compressed pellet methodology.

\section{Results and Discussion}

3.1. Compressive Strength of the Geopolymers. Figure 1 shows the effect of the activator concentration on the compressive strength of geopolymers at 3,7 , and $28 \mathrm{~d}$ with a solid/liquid ratio of $1.25: 1$. The compressive strength increases with increasing the activator concentration under the same modulus. The compressive strength at $3 \mathrm{~d}(6.70 \mathrm{MPa}), 7 \mathrm{~d}$ $(7.77 \mathrm{MPa})$, and $28 \mathrm{~d}(11.65 \mathrm{MPa})$ is the lowest when the sodium silicate modulus is 1.5 and the activator concentration is $30 \%$. The compressive strength is the highest when the activator concentration is $70 \%$, reaching $30.45 \mathrm{MPa}(3 \mathrm{~d})$ and $32.23 \mathrm{MPa}(7 \mathrm{~d})$, and $32.27 \mathrm{MPa}(28 \mathrm{~d})$. The phenomenon of "flash coagulation" appeared when the activator concentration exceeds $70 \%$, which makes geopolymers difficult to apply. There is a similar result when the sodium silicate modulus is 2. A low modulus is beneficial to the slag hydration reaction, and polymerization proceeds more easily, but a modulus that is too large is not conducive to the formation of early strength under the same activator concentration.

Figure 2 shows the $7 \mathrm{~d}$ and $28 \mathrm{~d}$ compressive strengths of geopolymers at various solid/liquid ratios. The compressive strength increases with increasing solid-liquid ratio. At the same solid/liquid ratio $(28 \mathrm{~d})$, when the activator concentration is $30 \%$, the increase is the largest, from $7.23 \mathrm{MPa}$ to 17.92 MPa, but the smallest increase is at $70 \%$, from $27.43 \mathrm{MPa}$ to $32.62 \mathrm{MPa}$. This is probably due to the increase in the solid/liquid ratio, increasing the mass fraction of slag powder in the geopolymer. The contact between the activator concentration and the reacting materials improved [11]. More slag participates in the reaction, resulting in a denser structure and higher compressive strength.

3.2. Flexural Strength of the Geopolymers. Figure 3 shows the influence of the activator concentration on the geopolymers flexural strength at a solid/liquid ratio of $1.25: 1$. The sodium silicate modulus has little effect on the flexural strength. The flexural strength first increases subsequently and decreases with increasing activator concentrations. The flexural strength ( $28 \mathrm{~d})$ is the highest when the activator concentration is $40 \%$, reaching $5.45 \mathrm{MPa}$ (modulus of 1.5 ) and $5.33 \mathrm{MPa}$ (modulus of 2), respectively. However, the flexural strength shows a sharp decrease when the activator concentration exceeds $40 \%$. There is a certain relationship between the degree of shrinkage cracking and flexural strength. The increase in activator concentration promotes the ion reaction in solution to produce more calcium aluminosilicate and silicic acid $\left(\mathrm{H}_{2} \mathrm{SiO}_{3}\right)$, which leads to a sharp decrease in geopolymers flexural strength [30].

Figure 3 indicates that when the activator concentration is $40 \%$, the flexural strength is optimum. The effect of the solid/ liquid ratio on the flexural strength is shown in Figure 4 (the sodium silicate modulus is 1.5 with an alkali concentration of 40\%). The results show that the flexural strength increases with increasing solid/liquid ratio. When the solid/liquid ratio is $1: 1$, the flexural strength is the lowest, reaching $4.12 \mathrm{MPa}$ at $28 \mathrm{~d}$. When the solid/liquid ratio is $1.75: 1$, the flexural strength is the highest, reaching $7.75 \mathrm{MPa}$ at $28 \mathrm{~d}$. Geopolymers may collapse from the excessive water used for preparation. The excess water is expected to evaporate in the process of condensation and hardening, leaving a large number of pores in the specimen and decreasing flexural strength.

3.3. Setting Time of the Geopolymers. Figure 5 shows the effect of the activator concentration and solid/liquid ratio on the geopolymer setting time. Both the initial and final setting times gradually decrease with increasing activator concentration. Under the same activator concentration, the difference between the initial and final setting times gradually decreases with increasing activator concentration. When the activator concentration is $\leq 40 \%$, the smaller the solid/liquid ratio is, the longer the initial setting time is. However, when the activator concentration is greater than $40 \%$, the higher the solid/liquid ratio is, the shorter the initial setting time is. The setting time is related to the degree of polymerization [31]. In an aqueous solution, $\mathrm{Na}^{+}$exists as a hydrated ion. As the activator concentration is enhanced, a large amount of water and $\mathrm{Na}^{+}$are required to form a hydrated state, resulting in the rapid reduction of free water and a shorter setting time. The solid/liquid ratio also influences the setting time. Weng and Sagoe-Crentsil [32] found that an increased amount of water accelerated dissolution and hydrolysis through the reaction heat curve but inhibited polymerization. That is, the increased water prolonged the setting time. Therefore, it is important to select an appropriate solid/liquid ratio to control the geopolymer setting time. The required setting time depends on the application. For example, a higher solid/liquid ratio can be chosen to shorten the 

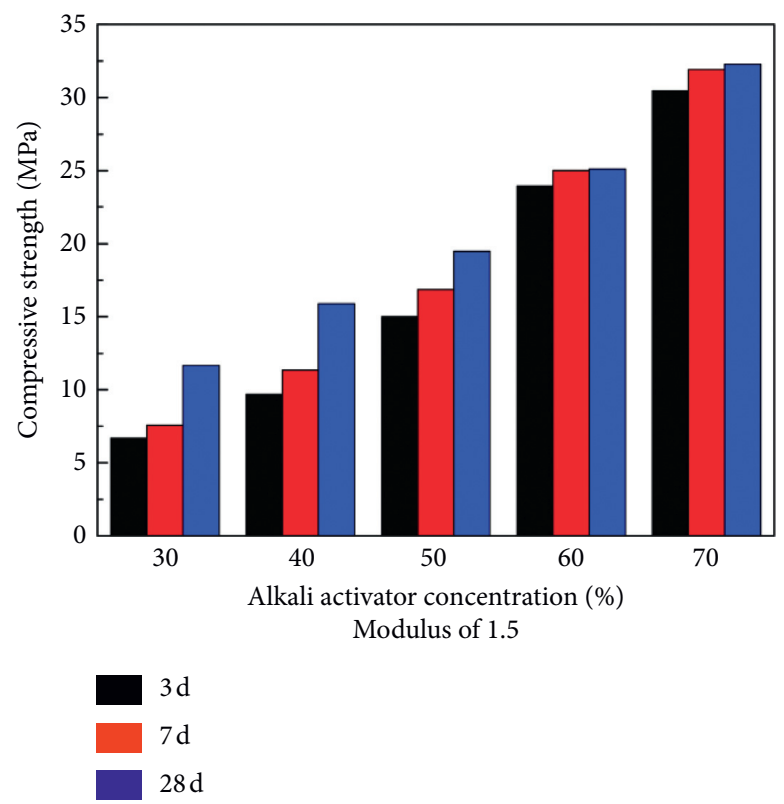
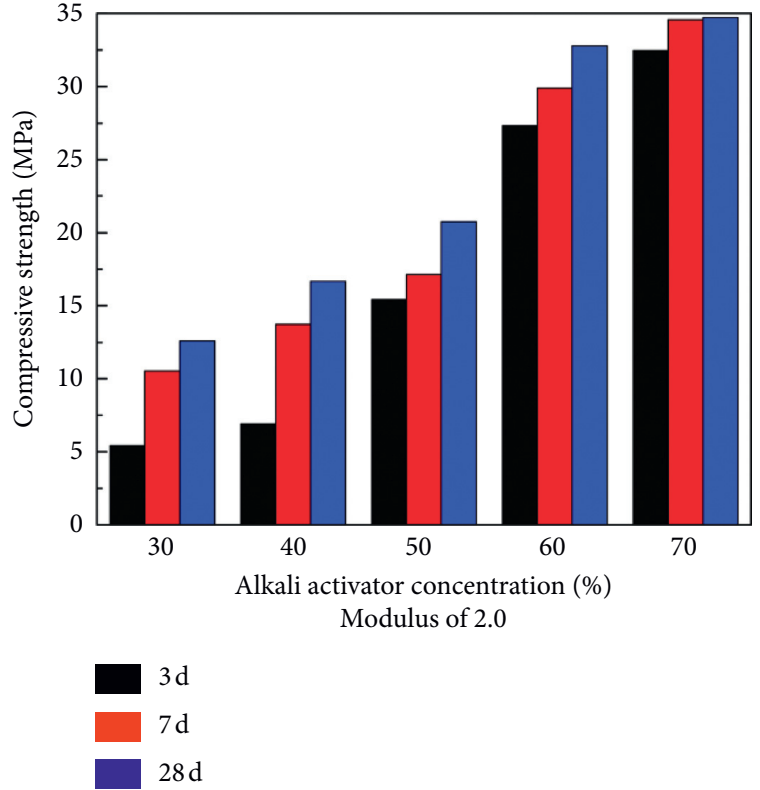

(a)

(b)

FIGURE 1: Influence of the activator concentration on the compressive strength of geopolymers.

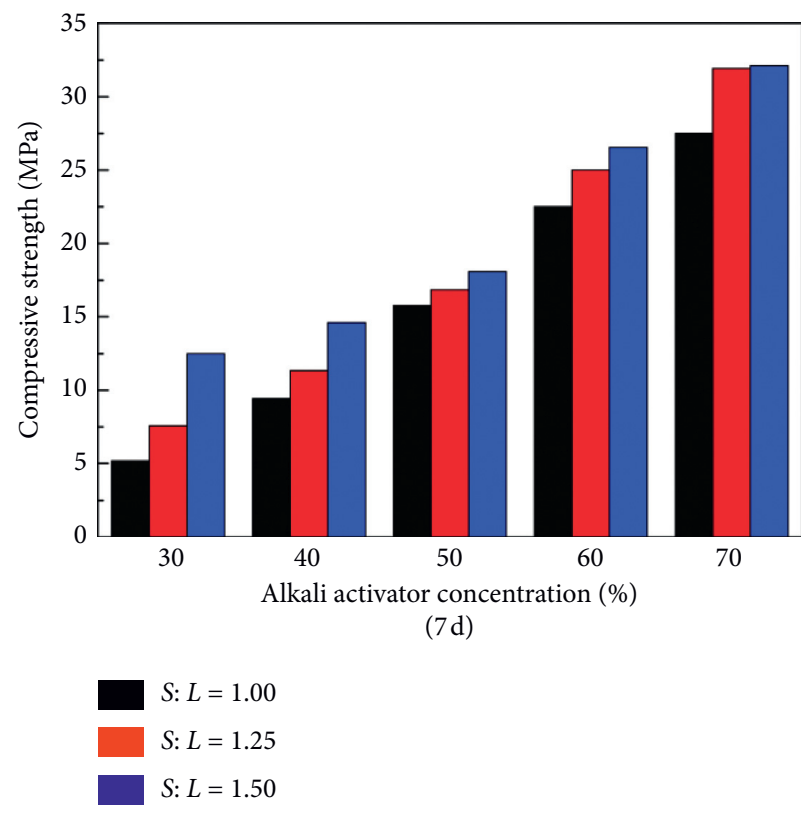

(a)

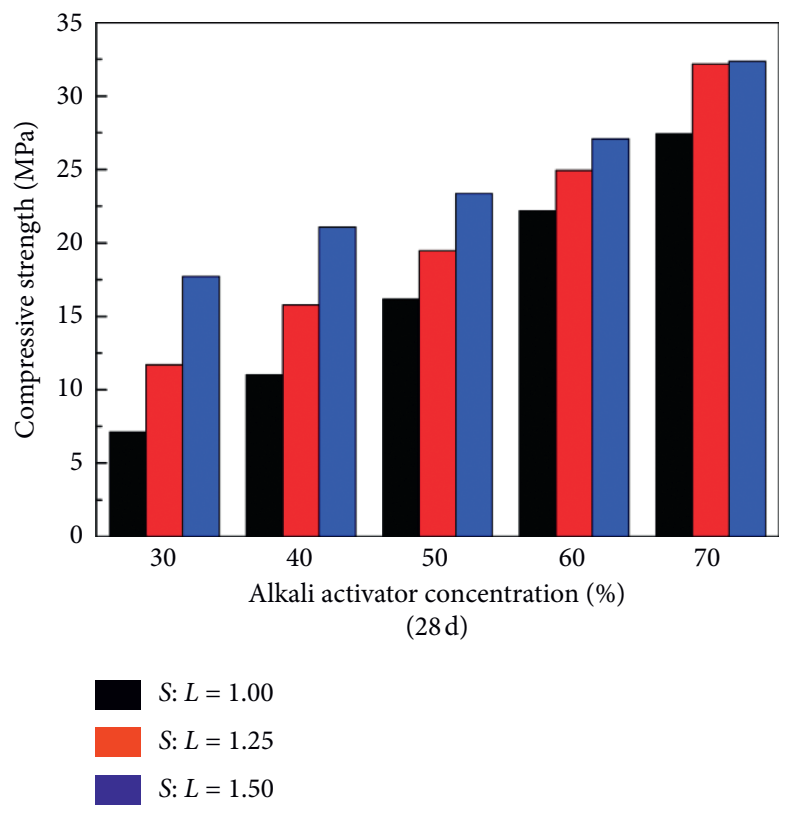

(b)

FIGURE 2: Influence of the solid/liquid ratio on the compressive strength.

setting time when geopolymers are used for the rapid repair of pavement and airport runways. A lower solid/liquid ratio can be chosen for geopolymer cement to avoid premature setting during transportation and pouring.

\subsection{Shrinkage Properties of the Geopolymers. Figures 6 and 7} show the geopolymer plastic shrinkage cracking morphologies and statistics. The number of cracked blocks in the geopolymer increases with increasing activator concentration and decreases with increasing solid/liquid ratio. When the activator concentration is small, no shrinkage cracks are found on the geopolymer surfaces. However, the geopolymers tend to exhibit more obvious shrinkage cracks with increasing activator concentration. The shrinkage block area is large, and warping appears at the sample outer edges.

Geopolymer cracking is related to the sodium silicate modulus, activator concentration, and solid/liquid ratio, as shown in Figure 7. A larger sodium silicate modulus leads to a smaller geopolymer plastic shrinkage. A smaller activator 


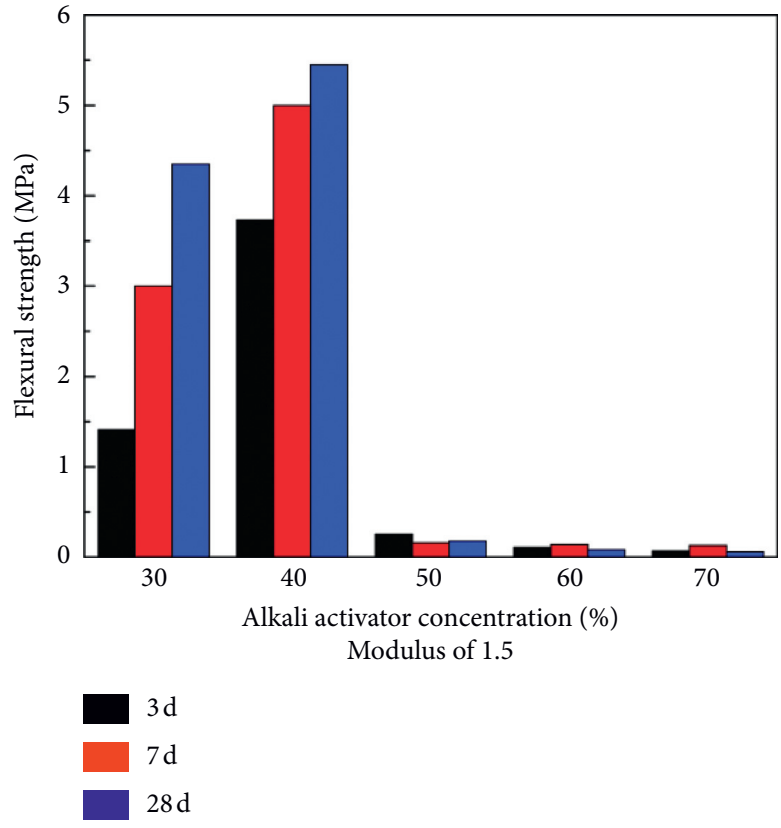

(a)

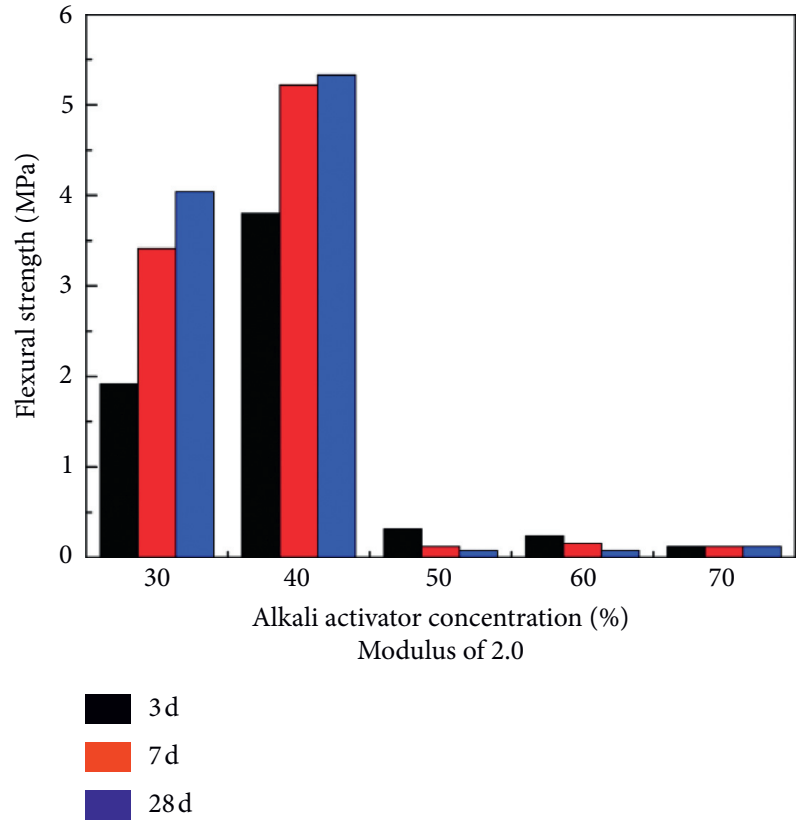

(b)

Figure 3: Influence of activator concentration on geopolymer flexural strength.

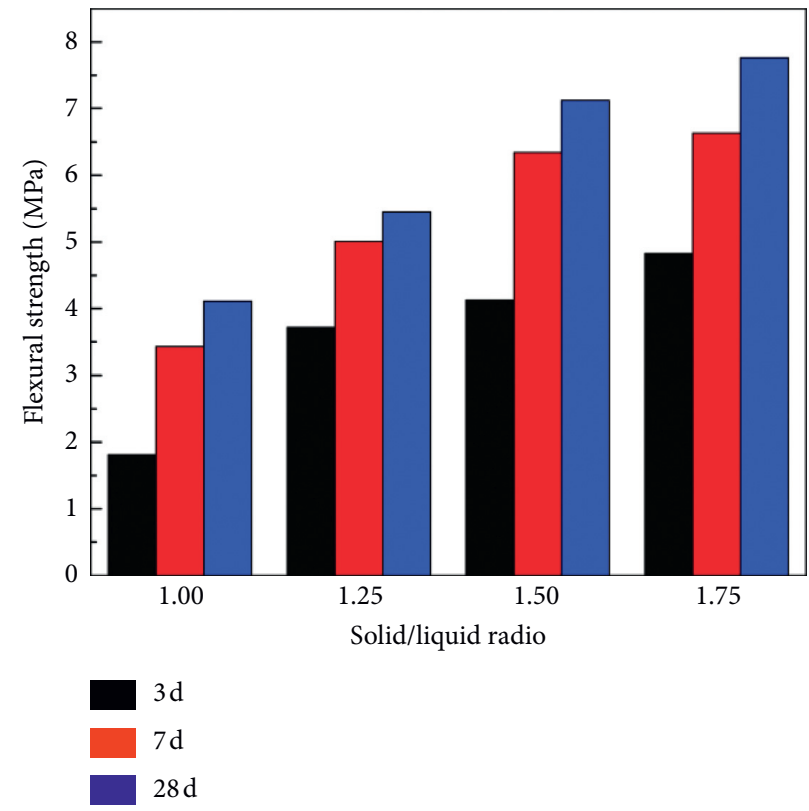

Figure 4: Influence of the solid/liquid ratio on geopolymer flexural strength.

concentration leads to smaller plastic shrinkage. The increase in activator concentration promotes aluminosilicate dissolution and depolymerization in slag, resulting in strong alkali metal cations binding in the structure and reduces excess alkali metal cations and other free ions $[8,33]$, thereby compacting the geopolymer microstructure. Moreover, the reaction of silicic acid produces by sodium silicate hydrolysis with calcium hydroxide produces by slag hydration the formed traces of C-S-H gel (calcium silicate hydrate). The formation of low content of C-S-H gel can destroy the equilibrium of multiphase ions and further promote the dissolution of calcium oxide in the slag until the dissolution of calcium oxide makes the slurry more compact. Therefore, a higher activator concentration promotes the hydration reaction and the degree of geopolymer polymerization. However, if the activator concentration is too high, the degree of polymerization would be too large, and the gel content would be too high $(>50 \%)$, resulting in more severe shrinkage cracking, which is unfavourable to the shrinkage resistance of hardened pastes. 


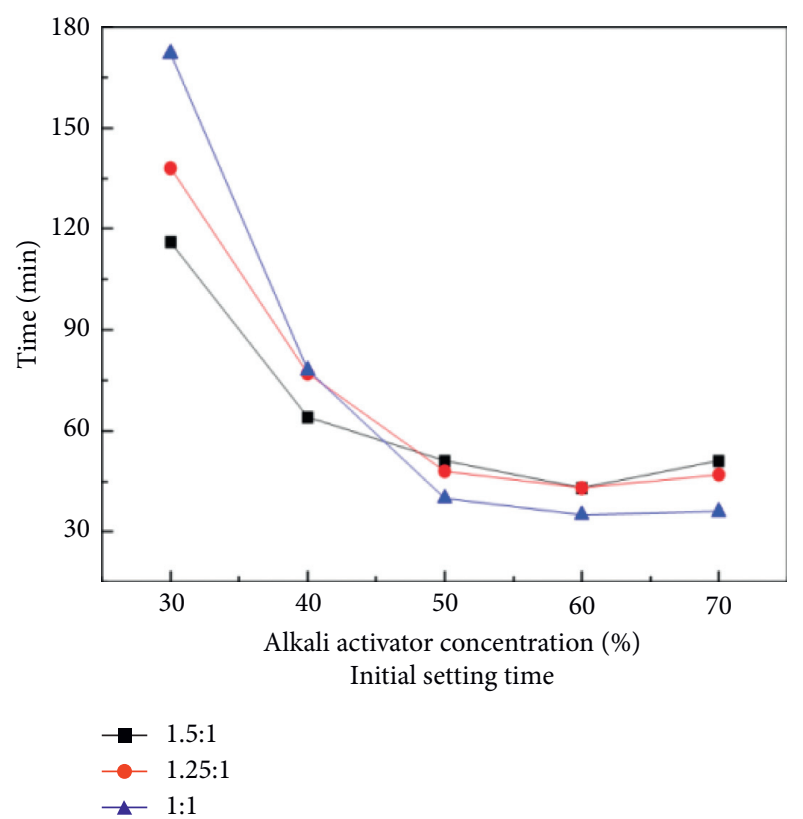

(a)

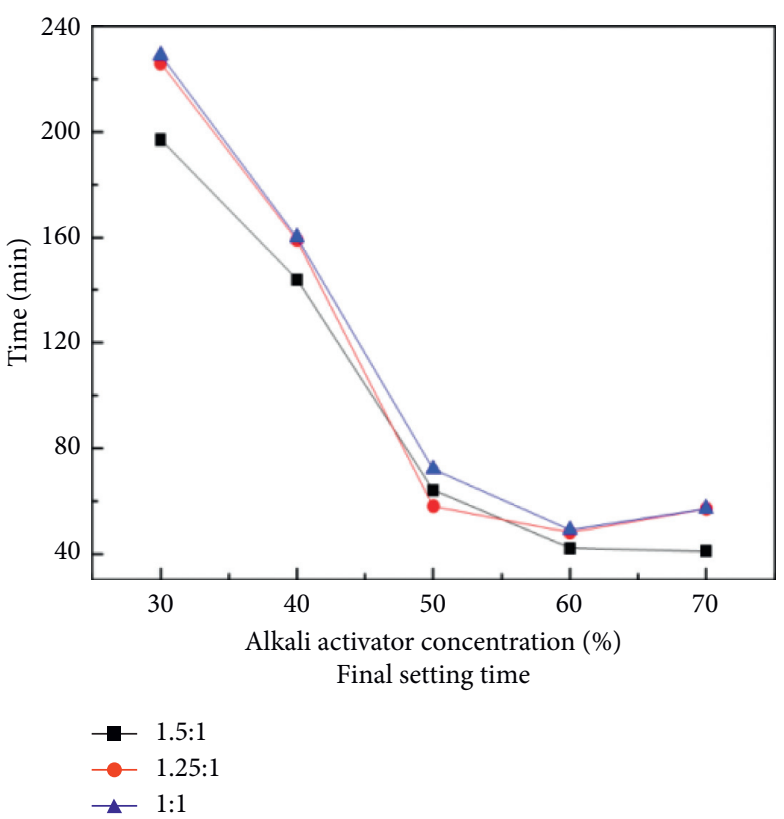

(b)

Figure 5: Influence of the solid/liquid ratio on the setting time.

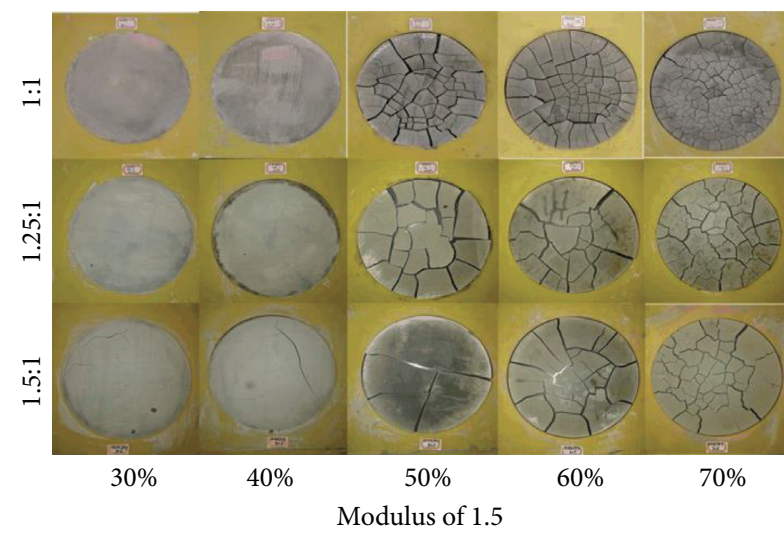

(a)

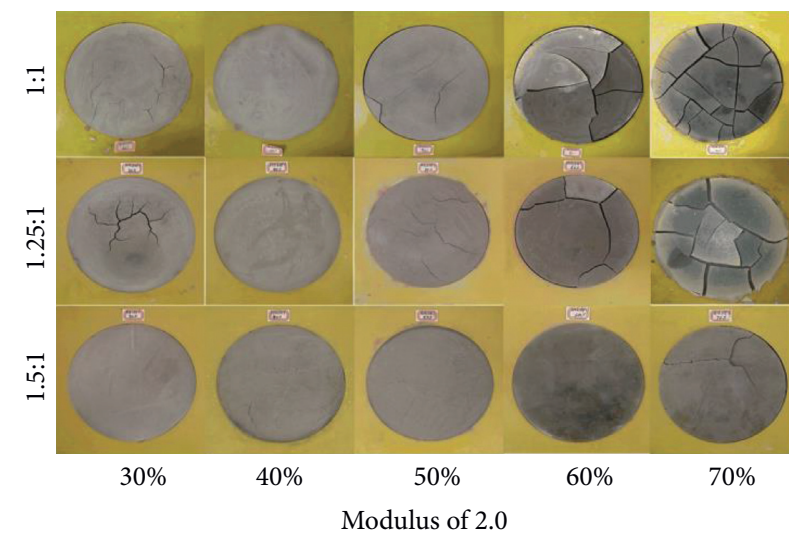

(b)

FIGURE 6: Shrinkage morphologies of geopolymer blocks with different sodium silicates.

The activator concentration is the key factor affecting the slag-based geopolymer properties. Samples with an activator concentration mixture ratio of approximately $40 \%$ are chosen for further drying shrinkage tests. Figure 8 shows the drying shrinkage of geopolymers with different activator concentrations. The drying shrinkage increases with increasing activator concentration and curing age. In the initial curing stage, the drying shrinkage changes significantly, but the difference between different activator concentrations is less obvious. The drying shrinkage (at $14 \mathrm{~d}$ of curing) with $36 \%$ and $42 \%$ activator concentrations are $108 \times 10^{-5}$ and $119 \times 10^{-5}$, respectively, and the difference is only $11 \times 10^{-5}$. After $14 \mathrm{~d}$, the increased shrinkage gradually plateaued, but the drying shrinkage of the samples prepared with different activator concentrations become larger. The drying shrinkage of samples prepared with $42 \%$ activator concentration is the largest $\left(188 \times 10^{-5}\right)$ and that with $36 \%$ is the smallest $\left(148 \times 10^{-5}\right)$ at $56 \mathrm{~d}$.

Figure 9 shows geopolymer drying shrinkage with an activator concentration of $40 \%$. The solid/liquid ratio has little effect on the drying shrinkage in the early stage. After $14 \mathrm{~d}$, the difference between the different solid/liquid ratios gradually increases with increasing solid/liquid ratio. The drying shrinkage rate first increases and subsequently decreases. When the sodium silicate modulus is 1.5 , the drying shrinkage increased with increasing solid/liquid ratio. The minimum drying shrinkage of geopolymers with a solid/liquid ratio of 1 : 1 is $151 \times 10^{-5}$ at $56 \mathrm{~d}$, and the maximum drying shrinkage with a solid/liquid ratio of $1.5: 1$ is $171 \times 10^{-5}$. The increased solid/liquid ratio causes the activator to fully react with the slag to reduce the free water, water loss rate, and drying shrinkage. Rapid free water evaporation in the early curing 


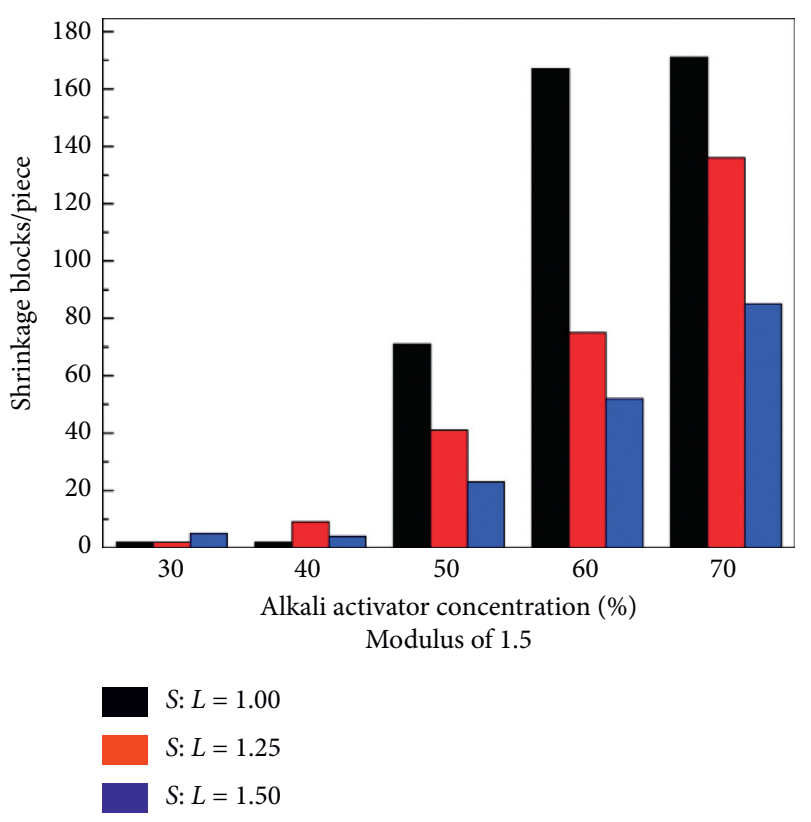

(a)

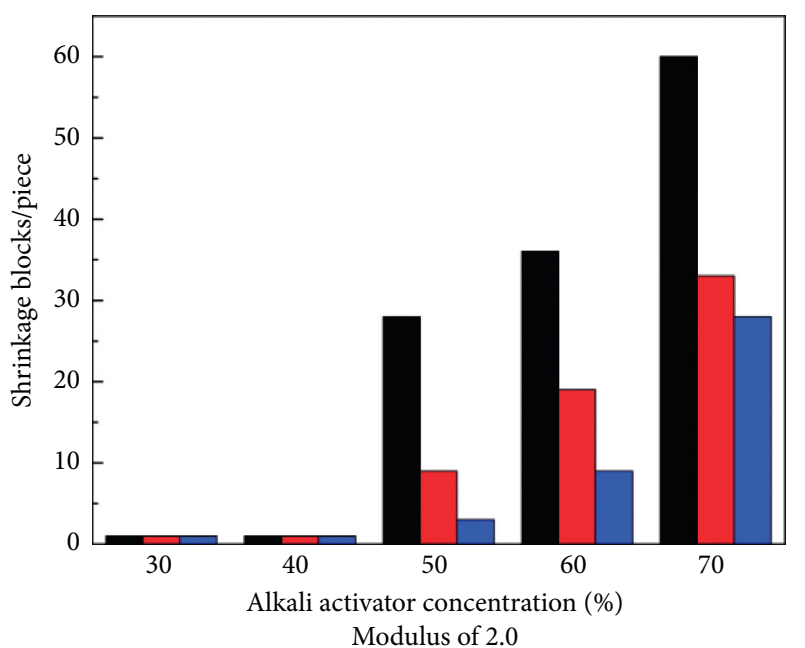

$S: L=1.00$

$S: L=1.25$

$S: L=1.50$

FIGURE 7: Influence of the sodium silicate modulus on the number of shrinking geopolymer blocks.

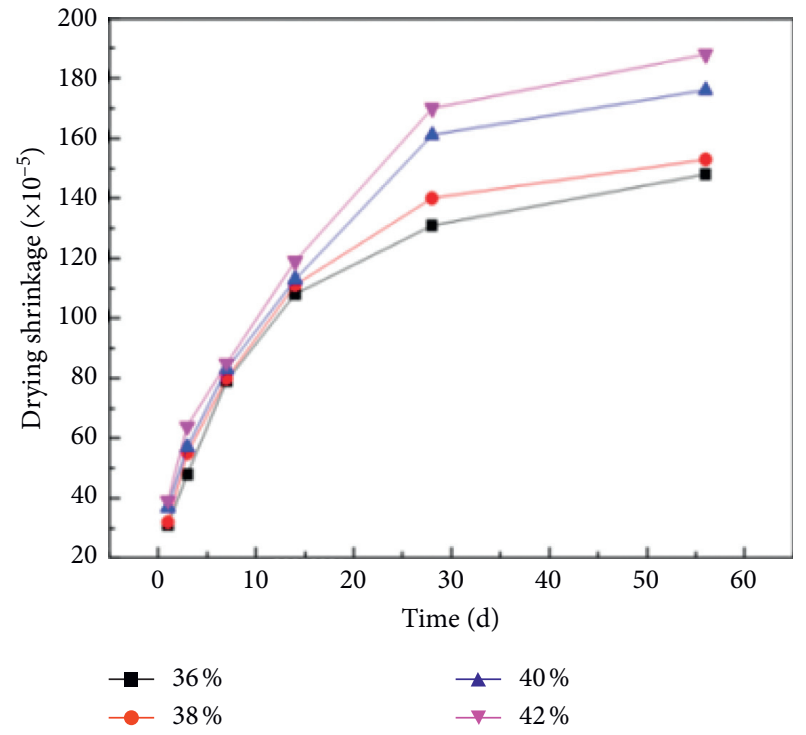

FIGURE 8: Influence of the activator concentration on the drying shrinkage rate of geopolymers.

stage increases the porosity of the geopolymers. The geopolymer becomes more stable in the later stage, thereby reducing the rate of drying shrinkage [23].

3.5. Microstructure Analysis of the Geopolymers. Figure 10 shows SEM photos of geopolymers after 28 days of curing with different activator concentrations and a solid/liquid ratio of $1.25: 1$. The slag surface is rough, and there are obvious differences in the microstructure of geopolymers prepared with different activator concentrations. When the activator concentration is $30 \%$ and $40 \%$, the geopolymer surface is uneven

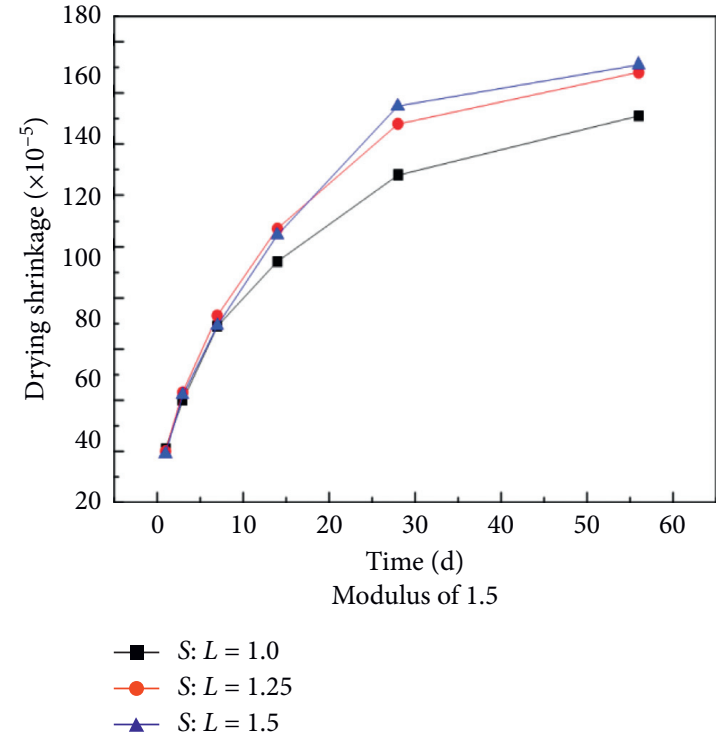

Figure 9: Influence of the solid/liquid ratio on the drying shrinkage of geopolymers.

and relatively rough. When the activator concentration continues to increase, there are a larger number of cracks distributed inside the sample, which results in stress concentrations and reduces its mechanical properties. It should be noted that with increasing activator concentration, $\mathrm{Ca} / \mathrm{Si}$ and $\mathrm{Si} / \mathrm{Al}$ gradually increases. The amount of $[\mathrm{SiO} 4]^{4-}$ and $[\mathrm{AlO} 4]^{5-}$ monomers increases so that the $\mathrm{Si}-\mathrm{O}-\mathrm{Si}$ or $\mathrm{Si}-\mathrm{O}-\mathrm{Al}$ increases and forms more aluminosilicate skeletons, which are conducive to C-A-S-H gel formation [34, 35]. However, the degree of shrinkage cracking increases with increasing activator concentration. Excessive shrinkage leads to specimen damage 


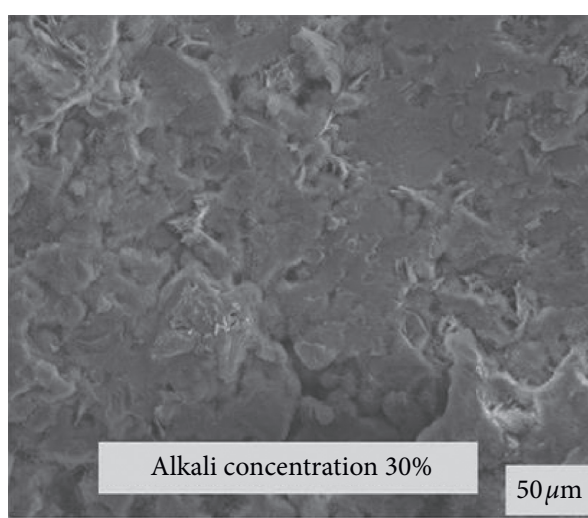

(a)

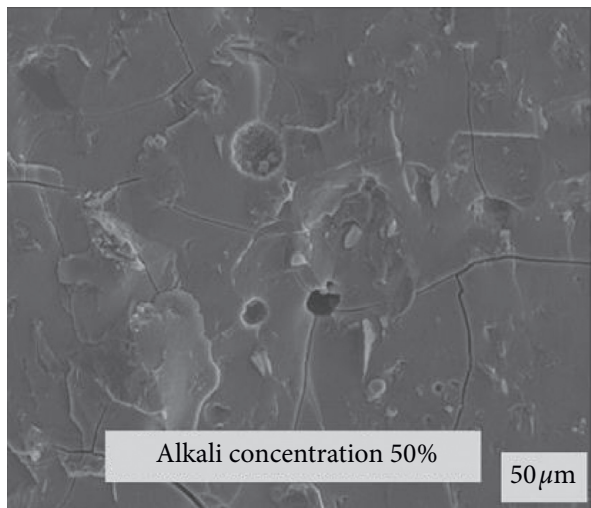

(c)

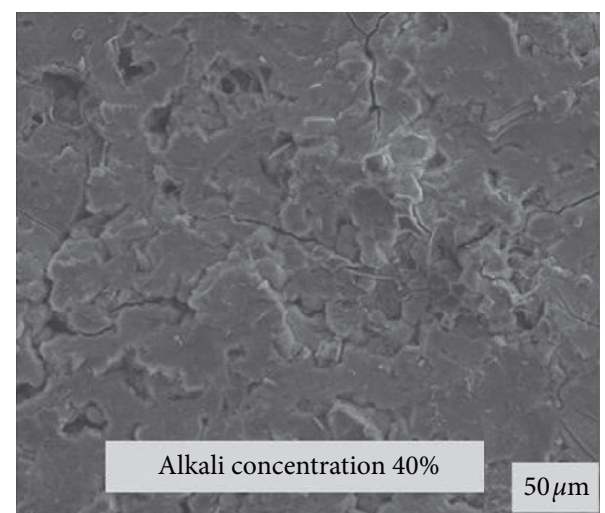

(b)

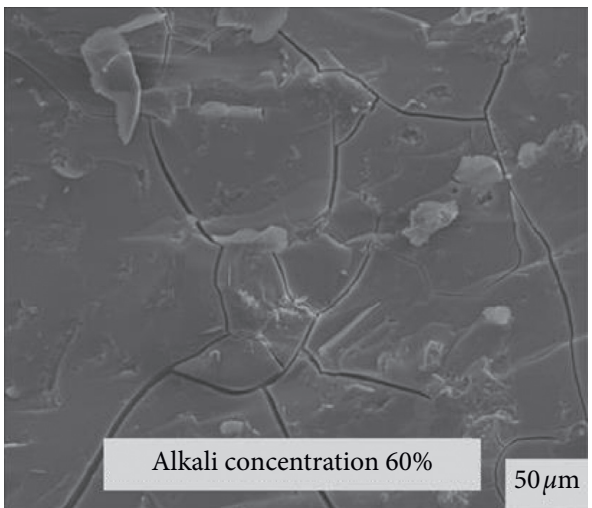

(d)

FIGURE 10: SEM images of sections of geopolymer blocks.

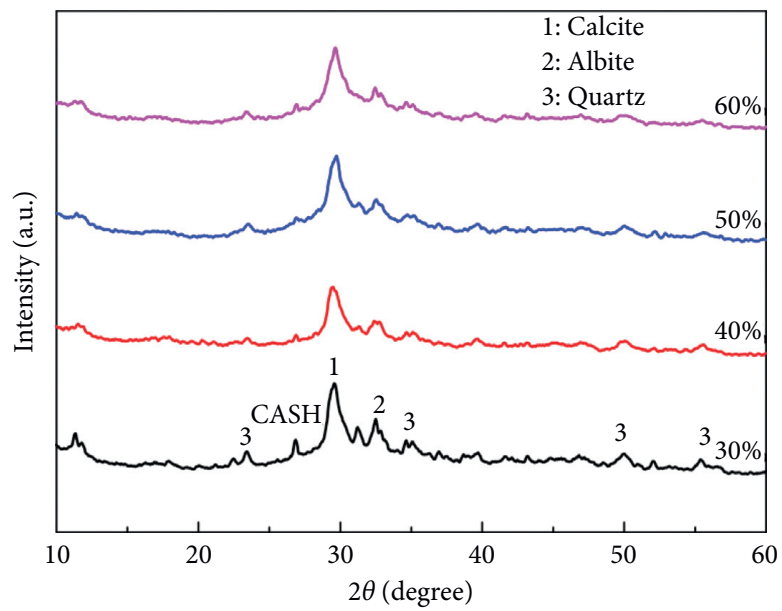

FIGURE 11: XRD pattern of geopolymers.

cracks, so the flexural strength of the geopolymer increases first and then decreases with increasing activator concentration [36].

\subsection{Composition Analysis of the Geopolymers}

3.6.1. XRD Analysis. Geopolymer X-ray diffraction patterns with a solid/liquid ratio of 1.25:1 after $28 \mathrm{~d}$ of curing are presented in Figure 11. The X-ray diffraction patterns of different activator concentrations are almost the same, and the main crystalline phase is quartz [37]. In addition to quartz, the presence of some other phases such as calcite, albite, and C-A-S-H is observed. The "bulge peak" at approximately $29.6^{\circ}(2 \theta)$ is the result of the short range of the $\mathrm{CaO}-\mathrm{SiO}_{2}-\mathrm{Al}_{2} \mathrm{O}_{3}-\mathrm{MgO}$ glassy structure of the slag [38]. The peak intensity decreases with increasing activator concentration. The C-A-S-H gel content increases as the reaction proceeded, resulting in a denser geopolymer structure. Therefore, the early compressive strength is higher. 


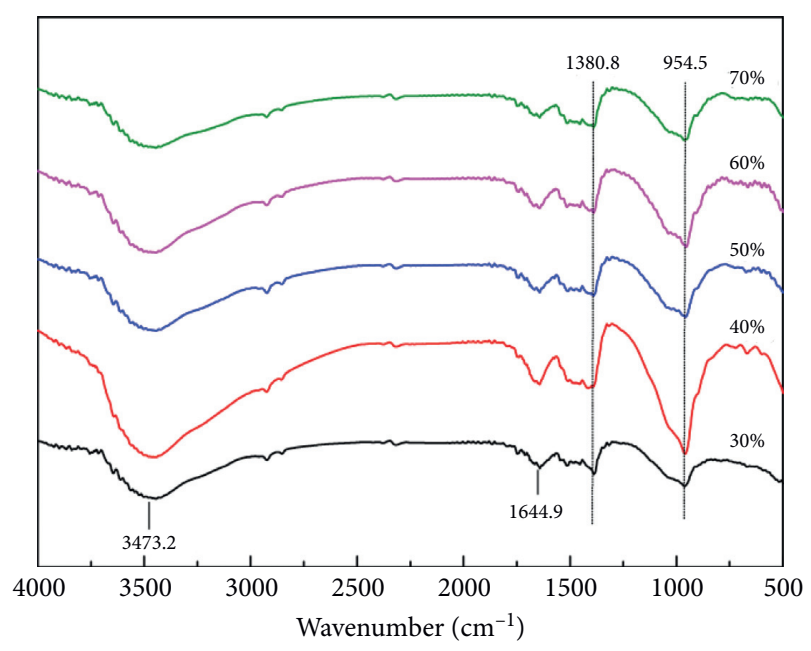

FIGURE 12: FTIR spectra of the geopolymers.

3.6.2. FTIR Analysis. Figure 12 shows the geopolymer FTIR spectra at $28 \mathrm{~d}$ under different activator concentrations and a solid/liquid ratio of $1.25: 1$. The geopolymers exhibit four distinct vibration peaks at $954.5,1380.8,1644.9$, and $3473.2 \mathrm{~cm}^{-1}$. The $-\mathrm{OH}$ stretching and $\mathrm{H}-\mathrm{O}-\mathrm{H}$ bending vibration bands at 3473.2 and $1650.0 \mathrm{~cm}^{-1}$ correspond to the chemically bound water molecules in the products. The $\mathrm{O}-\mathrm{C}-\mathrm{O}$ vibration peak at $1380.8 \mathrm{~cm}^{-1}$ corresponds to the carbonation products. The vibration peak at $954.3 \mathrm{~cm}^{-1}$ is assigned to the vibration of the asymmetric functional group $\mathrm{T}-\mathrm{O}-\mathrm{Si}$ ( $\mathrm{T}$ refers to $\mathrm{Si}$ or $\mathrm{Al}$ ), corresponding to the silicon tetrahedron of the $\mathrm{N}-\mathrm{A}-\mathrm{S}-\mathrm{H}$ gel phase in the product and the silicon tetrahedron structural unit $[39,40]$. The peak intensity of T-O-Si first increases when the activator concentration is less than $40 \%$ and then decreases. Therefore, $40 \%$ activator concentration is expected to promote the polymerization reaction most for the slag.

\section{Conclusions}

This study reported the effect of different factors on the strength and shrinkage of slag-based geopolymers. The main conclusions are as follows:

(1) The activator concentration is a key factor affecting slag-based geopolymer performance. The increasing activator concentration promotes the excitation reaction for slags to form products with a higher polymerization.

(2) The compressive strength of the geopolymers increases with increasing activator concentration. The increase in activator concentration first increases the flexural strength and then decreases, and the maximum is reached when the activator concentration is $40 \%$. The best mechanical properties occurred at $15.90 \mathrm{MPa}$ for the compressive strength and $5.45 \mathrm{MPa}$ for the flexural strength at $28 \mathrm{~d}$ when the solid/liquid ratio is $1.25: 1$.

(3) The activator concentration has an important influence on the setting time of geopolymers. The initial and final setting time decreases with increasing activator concentration.

(4) Geopolymer drying shrinkage increases with increasing activator concentration and decreases with increasing solid/liquid ratio. The alkali solution with a high modulus reduces the early hardening plastic shrinkage of geopolymer pastes but increases later drying shrinkage.

Using other raw materials, such as metakaolin and fly ash, for preparing geopolymers should be further investigated to optimize geopolymer properties. Furthermore, more attention should be paid to geopolymer maintenance to make them more suitable for practical projects.

\section{Data Availability}

The data used to support the findings of this study are included within the article.

\section{Conflicts of Interest}

The authors declare that they have no conflicts of interest.

\section{Acknowledgments}

This work was financially supported by the Natural Science Foundation of China (grant no. 51678534) and the Project of Science and Technology of Henan Transportation Department (grant no. 2018J4). Special thanks are due to Dr. Dan Wang of the Dalian University of Technology for her help with this article.

\section{References}

[1] J. Davidovits, "Geopolymers: inorganic polymeric new materials," Journal of Thermal Analysis and Calorimetry, vol. 37, pp. 1633-1656, 2005.

[2] L. Pelletier, F. Winnefeld, and B. Lothenbach, "The ternary system Portland cement-calcium sulphoaluminate clinkeranhydrite: hydration mechanism and mortar properties," Cement and Concrete Composites, vol. 32, no. 7, pp. 497-507, 2010.

[3] Y. S. Zhang, W. Su, Q. L. Chen, and L. Chen, "Synthesis and heavy metal immobilization behaviors of slag based geopolymer," Journal of Hazardous Materials, vol. 143, pp. 206-213, 2007.

[4] D. V. Reddy, J. B. Edouard, and K. Sobhan, "Durability of fly ash based geopolymer structural concrete in the marine environment," Journal of Materials in Civil Engineering, vol. 25, pp. 781-787, 2012.

[5] C. Suksiripattanapong, S. Horpibulsuk, P. Chanprasert, P. Sukmak, and A. Arulrajah, "Compressive strength development in fly ash geopolymer masonry units manufactured from water treatment sludge," Construction and Building Materials, vol. 82, pp. 20-30, 2015.

[6] X. Guo and X. Pan, "Mechanical properties and mechanisms of fiber reinforced fly ash-steel slag based geopolymer mortar," Construction and Building Materials, vol. 179, pp. 633641, 2018.

[7] C. D. Atiş, C. Bilim, Ö. Çelik, and O. Karahan, "Influence of activator on the strength and drying shrinkage of alkali- 
activated slag mortar," Construction and Building Materials, vol. 23, pp. 548-555, 2007.

[8] S. Aydın and B. Baradan, "Effect of activator type and content on properties of alkali-activated slag mortars," Composites Part B: Engineering, vol. 57, pp. 166-172, 2014.

[9] L. P. Liu, H. Tan, J. X. Deng, P. Z. Kuang, and Y. He, "Properties and reaction mechism of blast furnace slag based geopolymer dry power materials," The Journal of Wuhan University of Technology-Materials Science Edition, vol. 36, pp. 36-40, 2014, in Chinese.

[10] H. Cheng, K.-L. Lin, R. Cui, C.-L. Hwang, T.-W. Cheng, and Y.-M. Chang, "Effect of solid-to-liquid ratios on the properties of waste catalyst-metakaolin based geopolymers," Construction and Building Materials, vol. 88, pp. 74-83, 2015.

[11] C. Y. Heah, H. Kamarudin, A. M. Mustafa Al Bakri et al., "Study on solids-to-liquid and alkaline activator ratios on kaolin-based geopolymers," Construction and Building Materials, vol. 35, pp. 912-922, 2012.

[12] H. Bohlooli, A. Nazari, G. Khalaj, M. M. Kaykha, and S. Riahi, "Retracted: experimental investigations and fuzzy logic modeling of compressive strength of geopolymers with seeded fly ash and rice husk bark ash," Composites Part B: Engineering, vol. 43, no. 3, pp. 1293-1301, 2012.

[13] S. Alonso and A. Palomo, "Alkaline activation of metakaolin and calcium hydroxide mixtures: influence of temperature, activator concentration and solids ratio," Materials Letters, vol. 47, no. 1-2, pp. 55-62, 2001.

[14] X.-M. Cui, G.-J. Zheng, Y.-C. Han, F. Su, and J. Zhou, "A study on electrical conductivity of chemosynthetic $\mathrm{Al}_{2} \mathrm{O}_{3}$ $2 \mathrm{SiO}_{2}$ geoploymer materials," Journal of Power Sources, vol. 184, no. 2, pp. 652-656, 2008.

[15] T. W. Cheng and J. P. Chiu, "Fire-resistant geopolymer produced by granulated blast furnace slag," Minerals Engineering, vol. 16, no. 3, pp. 205-210, 2003.

[16] D. Bondar, C. J. Lynsdale, and N. B. Milestone, "Simplified model for prediction of compressive strength of alkali-activated natural pozzolans," Journal of Materials in Civil Engineering, vol. 24, 2016.

[17] S. Samantasingha and S. Prasad Singh, "Fresh and hardened properties of fly ash-slag blended geopolymer paste and mortar," The International Journal of Concrete Structures and Materials, vol. 13, pp. 1-12, 2019.

[18] M. Tuyan, Ö. Andiç-Çakir, and K. Ramyar, "Effect of alkali activator concentration and curing condition on strength and microstructure of waste clay brick powder-based geopolymer," Composites Part B: Engineering, vol. 135, pp. 242252, 2018.

[19] R. Z. Si, Q. L. Dai, S. C. Guo, and J. Q. Wang, "Mechanical property, nanopore structure and drying shrinkage of metakaolin-based geopolymer with waste glass powder," Journal of Cleaner Production, vol. 242, Article ID 118502, 2019.

[20] I. Khan, T. Xu, A. Castel, R. I. Gilbert, and M. Babaee, "Risk of early age cracking in geopolymer concrete due to restrained shrinkage," Construction and Building Materials, vol. 229, Article ID 116840, 2019.

[21] D. S. Perera, O. Uchida, E. R. Vance, and K. S. Finnie, "Influence of curing schedule on the integrity of geopolymers," Journal of Materials Science, vol. 42, no. 9, pp. 3099-3106, 2007.

[22] R. J. Thomas, D. Lezama, and S. Peethamparan, "On drying shrinkage in alkali-activated concrete: improving dimensional stability by aging or heat-curing," Cement and Concrete Research, vol. 91, 2017.
[23] T. Yang, H. Zhu, and Z. Zhang, "Influence of fly ash on the pore structure and shrinkage characteristics of metakaolinbased geopolymer pastes and mortars," Construction and Building Materials, vol. 153, pp. 284-293, 2017.

[24] P. S. Deb, P. Nath, and P. K. Sarker, "Drying shrinkage of slag blended fly ash geopolymer concrete cured at room temperature," Procedia Engineering, vol. 125, pp. 594-600, 2015.

[25] C. Ridtirud, P. Chindaprasirt, and K. Pimraksa, "Factors affecting the shrinkage of fly ash geopolymers," International Journal of Minerals, Metallurgy, and Materials, vol. 18, no. 1, pp. 100-104, 2011.

[26] K. Mermerdaş, Z. Algin, and Ş. Ekmen, "Experimental assessment and optimization of mix parameters of fly ash-based lightweight geopolymer mortar with respect to shrinkage and strength," Journal of Building Engineering, vol. 31, Article ID 101351, 2020.

[27] Y. Ling, K. Wang, and C. Fu, "Shrinkage behavior of fly ash based geopolymer pastes with and without shrinkage reducing admixture," Cement and Concrete Composites, vol. 98, pp. 74-82, 2019.

[28] P. Kamhangrittirong, P. Suwanvitaya, W. Witayakul, P. Suwanvitaya, and C. Chindaprasirt, "Factors influence on shrinkage of high calcium fly ash geopolymer paste," Advanced Materials Research, vol. 610, pp. 2275-2281, 2013.

[29] D. Shen, C. Wen, J. Kang, H. Shi, and Z. Xu, "Early-age stress relaxation and cracking potential of high-strength concrete reinforced with Barchip fiber," Construction and Building Materials, vol. 258, Article ID 119538, 2020.

[30] J. I. Escalante-Garćia, A. V. Gorokhovsky, G. Mendoza, and A. F. Fuentes, "Effect of geothermal waste on strength and microstructure of alkali-activated slag cement mortars," Cement and Concrete Research, vol. 33, pp. 1567-1574, 2003.

[31] H. Peng, S. L. Li, C. S. Cai, X. F. Zhang, and C. Cui, "Study on effect of mix and curing conditions on the mechanical properties and setting time of metakaolin-based geopolymer," Bulletin of the Chinese Ceramic Society, vol. 33, pp. 2809-2817, 2014, in Chinese.

[32] L. Weng and K. Sagoe-Crentsil, "Dissolution processes, hydrolysis and condensation reactions during geopolymer synthesis: part I-Low Si/Al ratio systems," Journal of Materials Science, vol. 42, no. 9, pp. 2997-3006, 2007.

[33] S. Kumar, R. Kumar, and S. P. Mehrotra, "Influence of granulated blast furnace slag on the reaction, structure and properties of fly ash based geopolymer," Journal of Materials Science, vol. 45, no. 3, pp. 607-615, 2010.

[34] C. K. Yip, G. C. Lukey, and J. S. J. Deventer, "The coexistence of geopolymeric gel and calcium silicate hydrate at the early stage of alkaline activation," Cement and Concrete Research, vol. 35, pp. 1688-1697, 2004.

[35] C. K. Yip, G. C. Lukey, J. L. Provis, and J. S. J. van Deventer, "Effect of calcium silicate sources on geopolymerisation," Cement and Concrete Research, vol. 38, no. 4, pp. 554-564, 2008.

[36] B. S. Gebregziabiher, R. Thomas, and S. Peethamparan, "Very early-age reaction kinetics and microstructural development in alkali-activated slag," Cement and Concrete Composites, vol. 55, pp. 91-102, 2015.

[37] K. Gkhan, "The effect of high temperature on the design of blast furnace slag and coarse fly ash-based geopolymer mortar," Composites Part B: Engineering, vol. 92, pp. 9-18, 2016.

[38] S. Song and H. M. Jennings, "Pore solution chemistry of alkali-activated ground granulated blast-furnace slag," $\mathrm{Ce}$ ment and Concrete Research, vol. 29, no. 2, pp. 159-170, 1999. 
[39] A. Vásquez, V. Cárdenas, R. A. Robayo, and R. M. de Gutiérrez, "Geopolymer based on concrete demolition waste," Advanced Powder Technology, vol. 27, no. 4, pp. 1173-1179, 2016.

[40] R. A. Gado, M. Hebda, M. Łach, and J. Mikuła, "Alkali activation of waste clay bricks: influence of the silica modulus, $\mathrm{SiO}_{2} / \mathrm{Na}_{2} \mathrm{O}, \mathrm{H}_{2} \mathrm{O} / \mathrm{Na}_{2} \mathrm{O}$ molar ratio, and liquid/solid ratio," Materials, vol. 13, no. 2, p. 383, 2020. 